\title{
Effectiveness of acupressure on nausea and vomiting among cancer patients receiving chemotherapy in a selected hospital, Coimbatore.
}

\author{
Jagon.J.Babu \\ (Lecturer, School of Nursing, / Galgotias University, Greater Noida, Utter Pradesh, India)
}

\begin{abstract}
Chemotherapy induces nausea and vomiting. In this context; bio-field therapy like acupressure has its own significance, thus enhancing the scope of nursing. The main objective of the study was to evaluate the effectiveness of acupressure (p6) on nausea and vomiting among cancer patients receiving chemotherapy. A quantitative approach using Experimental design with pretest posttest was carefully utilized. For this 60 cancer patients receiving chemotherapy was selected using stratified random sampling in G.K.N.M Hospital. The intervention $p 6$ acupressure was given by the researcher thrice a day for three days. Data collected using Standardized Rhodes index of nausea and vomiting to assess the level of nausea and vomiting by interview method was analyzed using independent ' $t$ ' test and paired ' $t$ ' test that found significant values 15.12 and 9.14 respectively at $p<0.001$. Thus, the study finding point out the effectiveness of $p 6$ acupressure on nausea and vomiting among cancer patients receiving chemotherapy.

Keywords-Acupressure, Cancer, Chemotherapy, Nausea and Vomiting.
\end{abstract}

\section{INTRODUCTION}

Cancer is a class of disease in which group of cells display uncontrolled growth, invasions and sometime metastasis. Chemotherapeutic agents are the drug of choice generally cyto-toxic in nature, which can destroy cancer cells. Chemotherapy works by stopping or slowing the growth of cancer cells, which grow and divide quickly. It is noted that among chemotherapy side effects' the most distressful events are nausea and vomiting [1]. Even though drug therapies are widely practiced for nausea and vomiting control, it is found, not $100 \%$ effective [2]. In such cases, alternative therapy like p6 acupressure plays a vital role. Acupressure is non invasive pressure applied by the thumbs, fingers, and hands on the surface of the skin at key points (active acupressure). Mechanism of acupressure is based on a theory that body has a system of meridians through which energy (Qi) flows (Cohen and Doner 1996) [3] The greatest advantage of Acupressure is that it can be administered by health care providers, family members, or patient's themselves and does not involve puncture of the skin.

\section{METHODOLOGY}

Methodology deals with the research approach, research design, setting of the study, population, criteria for selection of sample, sample size, sampling technique, description of the tool, scoring procedure, data collection procedure, data analysis and protection of human rights [4] . According to Polit and Hungler, (2004) research methodology refers to the researcher ways of obtaining, organizing and analyzing data [5].

A Basic true experimental study was selected for the study with pre-test and post test design. The study samples were recruited as per Stratified random sampling technique. Here the population was divided into two stratum based on gender and then the researcher allocated the population, 50\% proportionately in experimental and control group respectively who met the inclusion and exclusion criteria. The tool designed for the study comprised demographical variables (Age, Gender, Diagnosis, Cycle of chemotherapy, Antiemetic drug receiving status). Meanwhile, the level of nausea and vomiting was assessed by Rhodes Index of Nausea and Vomiting scale. This consisted of 8 sub questions assessing subjective experience of nausea and vomiting. Domains of factors included frequency, amount, duration, severity and distress of each symptom. Among 8 sub questions, 5 questions were related to occurrence and 3 related to distress. The maximum score for occurrence was ' 4 ' and minimum score for occurrence was ' 0 ' with the total maximum score possible of ' 32 ' and the minimum possible of ' 0 '.

The data collection procedure was done for a stipulated period of 6 weeks among total of 60 samples with 30 each in experimental and control group respectively in oncology wards of G.K.N.M Hospital at Coimbatore after obtaining content validity from experts and doing a pilot study for the feasibility of the tool. During the main study, samples were also informed by the researcher about the nature and purpose of the study. The written consent was also obtained as per rule. The standardized, Rhodes Index of Nausea and Vomiting interview questionnaire was administered to assess pre-test score of nausea and vomiting on day 2 that was 
followed by the acupressure on $2^{\text {nd }}, 3^{\text {rd }}$ and $4^{\text {th }}$ day at $\mathrm{p} 6$ region. Post test was done on the $5^{\text {th }}$ day, i.e. at $120 \mathrm{hrs}$. As per protocol the acupressure at $\mathrm{p} 6$ was given 6hrs apart on each day with duration of each session lasting 5 minutes. On the $5^{\text {th }}$ day the same standardized, Rhodes Index of Nausea and Vomiting interview questionnaire was administered to assess the post test score of nausea and vomiting to experimental and control group.

III. ANALYSIS AND INTERPRETATIONS

Table 1: Frequency and percentage distribution of cancer patients receiving chemotherapy according to their selected demographic variables.

\begin{tabular}{|c|c|c|c|c|c|c|c|}
\hline \multirow[t]{2}{*}{ S.No. } & \multirow[t]{2}{*}{ Demographic Variables } & \multicolumn{2}{|c|}{$\begin{array}{l}\text { Experimental } \\
\text { Group }\end{array}$} & \multicolumn{2}{|c|}{$\begin{array}{c}\text { Control } \\
\text { Group }\end{array}$} & \multicolumn{2}{|c|}{ Total } \\
\hline & & $\mathrm{n}$ & $\%$ & $\mathrm{n}$ & $\%$ & $\mathrm{~N}$ & $\%$ \\
\hline \multirow[t]{5}{*}{1} & Age (in Years) & & & & & & \\
\hline & $18-40$ & 6 & 20 & 5 & 16.7 & 11 & 18.4 \\
\hline & $41-60$ & 11 & 36.7 & 13 & 43.3 & 24 & 40 \\
\hline & $61-80$ & 12 & 40 & 10 & 33.3 & 22 & 36.6 \\
\hline & 81 and above & 1 & 33.3 & 2 & 6.7 & 3 & 5 \\
\hline \multirow[t]{5}{*}{2} & Cycle of chemotherapy & & & & & & \\
\hline & a) $\quad 1^{\text {st }}$ Cycle & 17 & 56.7 & 16 & 53.3 & 33 & 55 \\
\hline & $2^{\text {nd }}$ Cycle & 9 & 30 & 8 & 26.7 & 17 & 28.3 \\
\hline & $3^{\text {rd }}$ Cycle & 4 & 13 & 4 & 13.3 & 8 & 13.3 \\
\hline & $4^{\text {th }}$ Cycle & 0 & 0 & 2 & 6.7 & 2 & 3.4 \\
\hline 3 & Anti-emetic drug receiving & 30 & 100 & 30 & 100 & 60 & 100 \\
\hline
\end{tabular}

It was inferred that, with regard to age, majority of the cancer patients receiving chemotherapy $24(40 \%)$ belonged to age group of $41-81$ years and $33(55 \%)$ belonged to $1^{\text {st }}$ cycle of chemotherapy. Meanwhile, majority of the cancer patients $20(33.3 \%)$ receiving chemotherapy were diagnosed with respiratory tract cancer and all 60(100\%) received anti-emetic drugs.

Table 2: Mean, Standard deviation, Mean difference and ' $t$ ' value of pre-test, post-test score of nausea and vomiting among cancer patients receiving chemotherapy in experimental and control Group.

\begin{tabular}{|c|c|c|c|c|c|}
\hline S. No. & Variables & Mean & SD & MD & 't' value \\
\hline 1 & Experimental group & 18.5 & 5.50 & & \\
& Pre test & 7.23 & 2.56 & 11.27 & $15.12^{* * *}$ \\
& Post test & & & & \\
& Control group & 18.03 & 5.3 & 1.59 & $2.90^{\mathrm{NS}}$ \\
\hline & Pre test & 16.44 & 4.87 & $* * *$ Significant at $\mathrm{p}<0.001$ level, NS - Not Significan \\
& Post test
\end{tabular}

Above table reveals that among experimental group, the mean pretest score 18.5 with standard deviation 5.50 was more than the mean post test score 7.23 with standard deviation 2.56 . The calculated mean difference was 11.27. The obtained ' $t$ ' value 15.12 was highly significant at $p<0.001$ level. On the other hand, among control group, the mean pretest score 18.03 with standard deviation 5.3 was more than the mean post test score 16.44 with standard deviation 4.87 . The calculated mean difference was 1.59 with the obtained ' $t$ ' value 2.90 that was not significant.

Hence, it is identified that acupressure is effective in reducing chemotherapy induced nausea and vomiting among cancer patients. 
Table 3: Mean, Standard Deviation, Mean Difference and ' $t$ ' value of post-test score of nausea and vomiting among cancer patients receiving chemotherapy in experimental and control group

\begin{tabular}{|c|c|c|c|c|c|}
\hline S. No & Variables & Mean & SD & MD & 't' value \\
\hline 1 & $\begin{array}{c}\text { Experimental group } \\
\text { Post test }\end{array}$ & 7.23 & 2.56 & & \\
2 & $\begin{array}{c}\text { Control group } \\
\text { Post test }\end{array}$ & 16.44 & 4.87 & 9.21 & $9.14 * * *$ \\
\hline
\end{tabular}

The above table reveals that the mean experimental group post test score 7.23 with standard deviation 2.56 was less than the control group mean post test score, 16.44 with a standard deviation 4.57 . The calculated mean deviation was 9.21. The obtained' $t$ ' value 9.14 was significant at $p<0.001$. Thus there was a significant difference between the experimental group post test score and control group post test score.

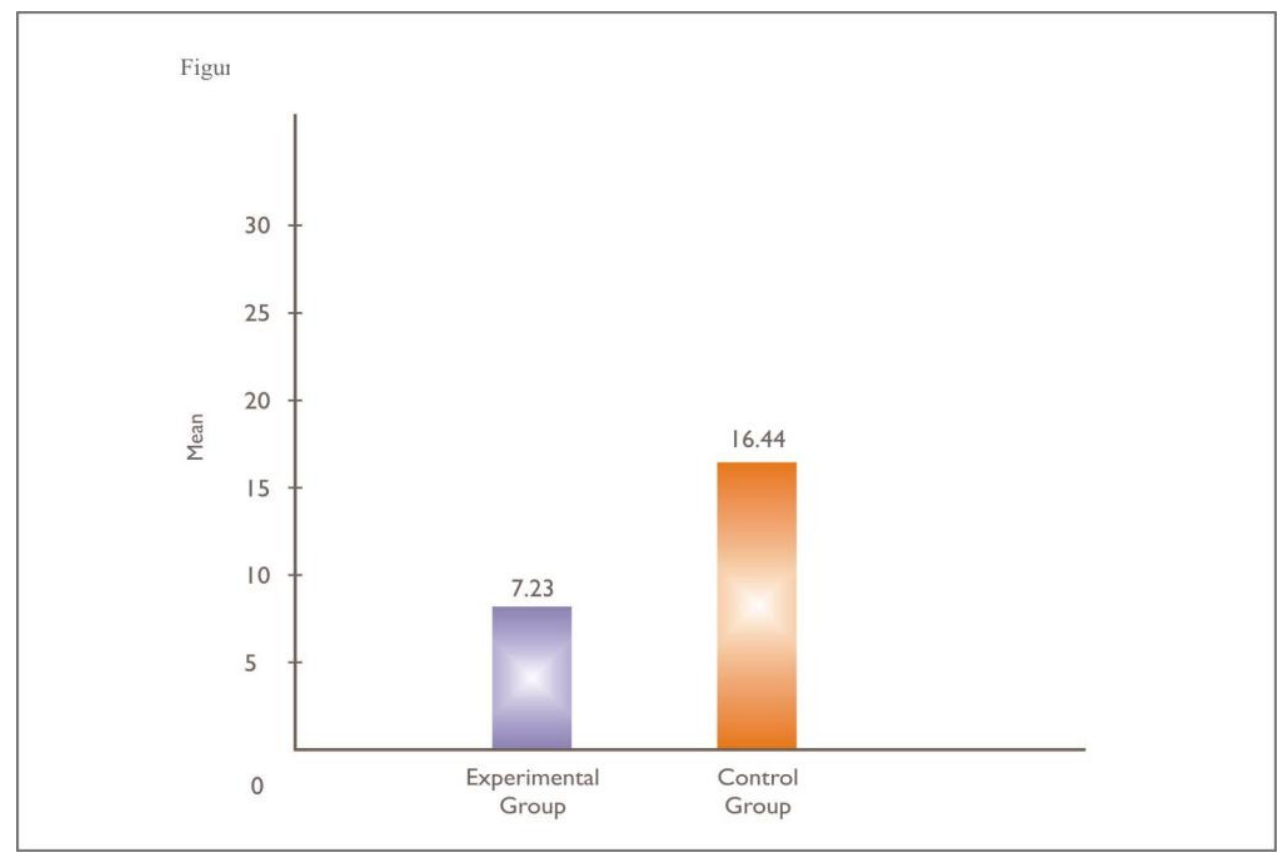

Fig 1: Bar diagram depicting the post test mean scores after acupressure among experimental and control group.

Thus it was inferred that acupressure is effective in reducing nausea and vomiting among cancer patients receiving chemotherapy. 
Table 4: Frequency, percentage and Chi square- distribution of level of nausea and vomiting among cancer patients receiving chemotherapy with their selected demographic variables.

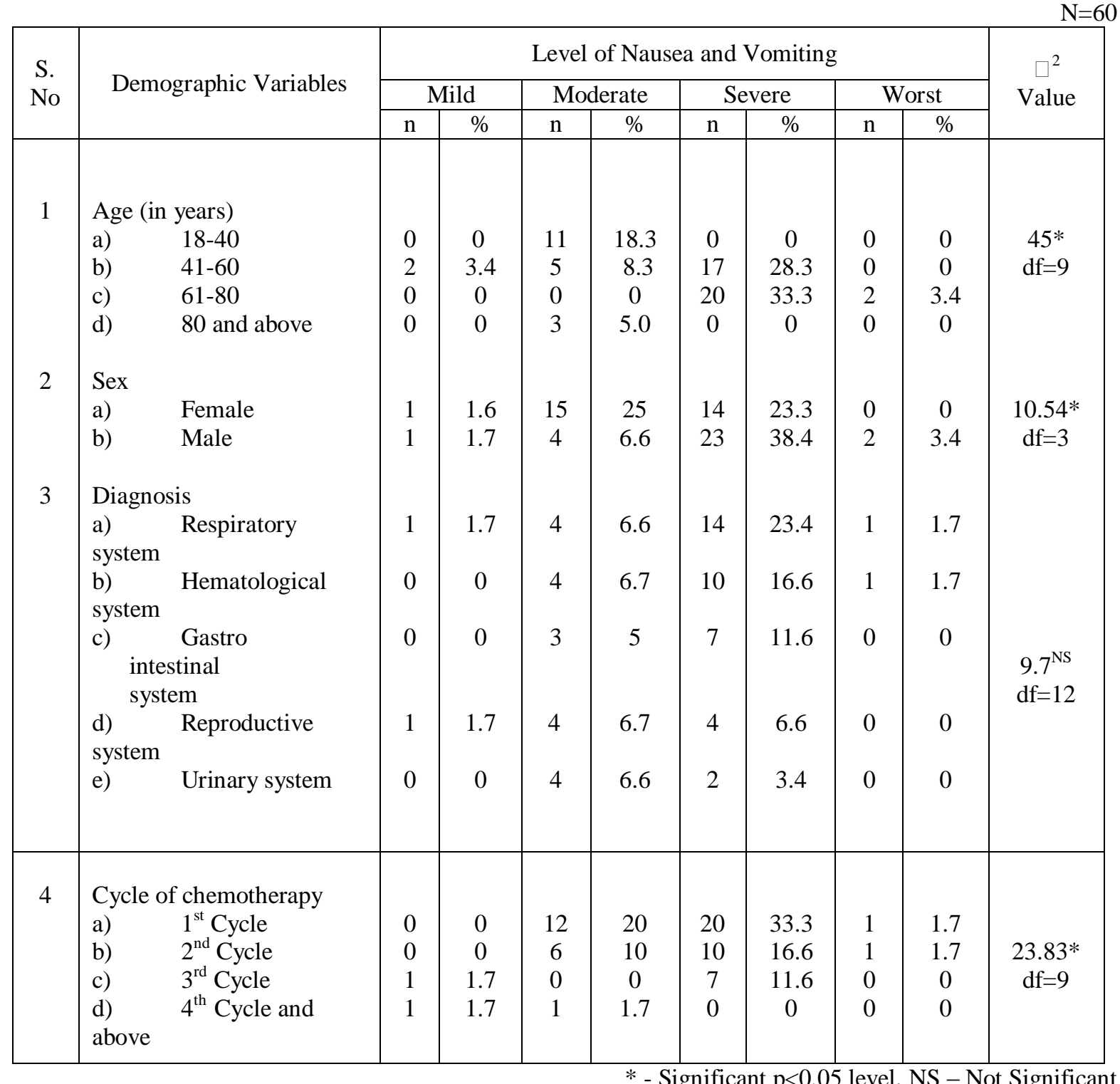

From the above table thus it is understood that that their was a significant association between the age, sex and cycle of chemotherapy among cancer patients receiving chemotherapy with their selected demographic variables hence the research hypotheses stated was supported.

\section{CONCLUSION}

The main conclusions drawn from this present study was that most of the cancer patients receiving chemotherapy had significant level of nausea and vomiting. After acupressure session, it is found that there had been a significant level of reduction in nausea and vomiting. Samples become familiar and found themselves comfortable and also expressed satisfaction. After the completion of the study, subjects in control group were demonstrated acupressure technique. It is thus concluded that, acupressure as an effective and simple strategy to reduce nausea and vomiting cancer patients receiving chemotherapy.

Implication in Nursing practice and education:

- Learn accurate assessment of nausea and vomiting using Rhodes index of nausea and vomiting.

- Understand the importance of acupressure as adjunct to the conventional anti-emetics.

- Encourage the importance of acupressure as a complimentary therapy.

- Learn accurate assessment of chemotherapy induced nausea and vomiting among cancer patients.

- Fresh hand training can be given to nurses to encourage patient practice of this simple technique. 
- Understand and bring to practice acupressure intervention.

Implication in nursing administration:

- In-service education programme can be organized for the nurses on this complimentary technique.

- The nurse can make cost effectiveness on the nursing care by reducing the usage of anti-emetics of cancer patients receiving chemotherapy.

Limitation:

- The study couldn't be done among patients with head and neck cancer.

- Restriction of sample size of 60 .

\section{ACKNOWLEDGEMENT}

I would like to acknowledge all the samples who has made my effort fruitified and accepting the new intervention in Indian clinical settings that is not been widely been practiced.

\section{REFERENCES}

[1] Chemotherpy/reducing sideeffects/chemo,:// www.pubmed . pmid: 8943569 Dated on 23.9.2008.

[2] Gilda's club worldwide: www.gildasclub.org Dated on 17.12.2005.

[3] National institute of health. http://www.nim.nih.gov/medline plus/cancer.html Dated on 23.7.2006.

[4] F. Polit, Nursing research principles and methods (Philadelphia: Lippincott Williams and Wilkins, 2004).

[5] F. Polit, and D. Hungler Nursing research principles and methods (Philadelphia: J.B. Lippincott, 2001). 